\title{
What is the impact of GOLD 2017 recommendations in primary care? - a descriptive study of patient classifications, treatment burden and costs [Erratum]
}

Gayle A, Dickinson S, Morris K, Poole C, Mathioudakis AG, Vestbo J. Int J Chron Obstruct Pulmon Dis. 2018;13: 3485-3492.

On page 3488, Results section, 2nd paragraph, first sentence, "When applying GOLD 2013 criteria, less than half of the cohort (46\%) was assigned to GOLD A or B, as compared to $86 \%$ when applying GOLD 2017 (Figure 1)" was incorrect. The corrected sentence is "When applying GOLD 2013 criteria, less than half of the cohort (46\%) was assigned to GOLD A or B, as compared to $84 \%$ when applying GOLD 2017 (Figure 1)". On page 3488, Results section, 2nd paragraph, third sentence, "Fifteen percentage $(n=2,939)$ of the total cohort could not be classified into the GOLD group due to missing symptom data (mMRC or CAT)" was incorrect. The corrected sentence is "Fifteen percent $(n=2,939)$ of the total cohort could not be classified into the GOLD group due to missing symptom data (mMRC or CAT)".

On page 3490, Discussion section, 5th paragraph, final sentence, "After excluding these patients, the proportion of patients who were classified as $\mathrm{C}$ or D decreased from $53 \%$ using GOLD 13\% to 16\% using GOLD 2017, consistent with our main findings suggesting that spirometry alone is not sufficient in distinguishing patients with overlap syndrome" was incorrect. The corrected sentence is "After excluding these patients, the proportion of patients who were classified as $\mathrm{C}$ or D decreased from 53\% using GOLD 2013 to $16 \%$ using GOLD 2017, consistent with our main findings suggesting that spirometry alone is not sufficient in distinguishing patients with overlap syndrome".
International Journal of COPD

\section{Publish your work in this journal}

The International Journal of COPD is an international, peer-reviewed journal of therapeutics and pharmacology focusing on concise rapid reporting of clinical studies and reviews in COPD. Special focus is given to the pathophysiological processes underlying the disease, intervention programs, patient focused education, and self management protocols.

\section{Dovepress}

This journal is indexed on PubMed Central, MedLine and CAS. The manuscript management system is completely online and includes a very quick and fair peer-review system, which is all easy to use. Visit http://www.dovepress.com/testimonials.php to read real quotes from published authors. 